\title{
ON THE PROBABILITY OF THEISM
}

\author{
Luis Rosa \\ Institute of Cultural Development
}

RESUMO: A proposição expressa por "Deus existe" (G), se é verdadeira ou falsa, ela é ou necessariamente verdadeira/falsa ou não necessariamente verdadeira/falsa. Em outras palavras, se G é capaz de ter um valor de verdade v, então ela é ou necessariamente v ou contingentemente v. por "Deus" eu quero significar um ser sobrenatural, com uma mente poderosa e imaterial que supostamente criou o universo. Certamente existem outros significados que estão vinculados a esse termo em certos contextos, mas os argumentos que eu irei avaliar aqui só fazem sentido sob essa interpretação.

\begin{abstract}
The proposition expressed by 'God exists' $(G)$, if it is true or false, is either necessarily true/false or not necessarily true/false. In other words, if $G$ is capable of having a truth-value $v$, then it is either necessarily $v$ or contingently $v$. By 'God' I mean a supernatural being, a powerful and immaterial mind that purportedly created the universe. Certainly there are other meanings that are attached to that term in certain contexts, but the arguments I will assess here only make sense under that interpretation.
\end{abstract}

The proposition expressed by 'God exists' $(G)$, if it is true or false, is either necessarily true/false or not necessarily true/false. In other words, if $G$ is capable of having a truth-value $v$, then it is either necessarily $v$ or contingently $v$. By 'God' I mean a supernatural being, a powerful and immaterial mind that purportedly created the universe. Certainly there are other meanings that are attached to that term in certain contexts, but the arguments I will assess here only make sense under that interpretation. We can discuss arguments involving other meanings attached to the term 'God' on another occasion. ${ }^{1}$

1 I often feel like it becomes completely pointless to talk about the existence of God under certain interpretations of the term 'God'. For example, some people say 'God is everything there is'. It is true that God exists in that sense, of course. But this is not what we want to know when we ask whether God 


\section{Dossiê Naturalismo, Dissertatio - Volume Suplementar 02 | UFPel [2015]}

Suppose that $G$ has truth-value $v$. Now suppose that $G$ is necessarily $v$ (that is, $G$ is necessarily true or $G$ is necessarily false). That means that $G$ cannot be $v^{\prime}$, where $v \neq v^{\prime}$ (e.g., $v$ is the value true and $v^{\prime}$ is the value false). If so, then nothing can raise or lower the objective probability of $G, C h(G)$. For example, if $G$ is necessarily true, then not only $C h(G)=1$, but also $C h(G \mid P)=1$, for any proposition $P$. That alethic status, however, is possessed only by tautologies (e.g., Fred is fred), logical or mathematical axioms and theorems (e.g., $p \rightarrow p,(\mathrm{x}+\mathrm{y})=(\mathrm{y}+\mathrm{x}))$, and so-called 'analytical truths' (e.g., that Every bachelor is an unmarried man). Similarly, the contrary alethic status of that status is reached only by negations of tautologies, axioms/theorems and analytic truths.

But $G$ is no tautology/negation of a tautology. And it is neither a mathematical or logical axiom/theorem, nor a mathematical or logical contradiction. Still, one might be tempted to suggest that $G$ could be an analytic truth. Consider typical examples of analytical truths. No one who is a competent user of the terms 'bachelor', 'unmarried', 'man', etc. seriously asks whether it is true that Every bachelor is an unmarried man. That proposition is sufficiently obvious to every such competent speaker. But $G$ is by no means obvious (the fact that there is so much controversy around it testifies that), and we seriously ask about its truth.

Of course, assuming that there is a substantial distinction between analytic and synthetic truths, it might be the case that some analytic truths are not obvious at all. Maybe $G$ is one of them. The proponent of that line of thought, however, would have to face two challenges. First, it has been pointed out that the relevant distinction does not really cut human thought

exists or not--we are not asking whether everything there is exists. (Similar observations apply to other cases involving supernatural terms, e.g., when we want to know whether spirits or souls exist but some people say that the spirit is a physical energy, or something like that). 
and language at its joints. ${ }^{2}$ Second, purported analytic truths that are somehow discovered or fleshed out are not really surprising after they have been discovered or fleshed out. Even when there is disagreement between conceptual analysts, they recognize each other's conceptual analyses as being very close to the establishment of necessary and sufficient conditions envisioned in their analytical endeavours. But if a conceptual analyst were to present us something like: $x$ is God if and only if (i) $x$ exists, (ii) such-and-such, (iii) so-and-so, etc., although we would probably be surprised, we would not accept it as a suitable analysis of 'God'.

It follows, then, that whatever truth-value $G$ has, it does not necessarily have that value. Let $q$ be the value such that $C h(G)=q$ (that is, the objective probability of $G$ is $q$ ). If what we said about the alethic status of $G$ is right, then it is possible for there to be certain facts $P$ such that $C h(G \mid P)<q$, and it is also possible for there to be certain facts $P^{\prime}$ such that $C h\left(G \mid P^{\prime}\right)>q$.

Given certain assumptions (involving both the syntax and the semantics of the formulas that constitute the arguments of probability functions), we can say the same thing about probability functions under other interpretations. In particular, we could say the same thing about an epistemic probability function $\operatorname{Pr}$. Here, of course, we talk about evidence instead of facts (without implying that no evidence is factive, of course): given $\operatorname{Pr}(G)=q$, there may be some piece of evidence $E$ such that $\operatorname{Pr}(G \mid E)<q$, as well as some further piece of evidence $E^{\prime}$ such that $\operatorname{Pr}\left(G \mid E^{\prime}\right)>q$. (From now on, whenever I use the term 'probability' I mean epistemic probability). ${ }^{3}$

So, just as we can say that the hypothesis that God exists is neither necessarily true nor necessarily false, so we can say that it is neither certainly

\footnotetext{
2 E.g., see Quine's classic (1951) and also Williamson (2007, Ch. 3-4). A good starting point for a problematization toward that distinction is to ask: What does it mean to say that a sentence or proposition is true 'solely in virtue of meaning', and not in virtue of how the world is?

${ }^{3}$ Probability functions are functions that obey to the usual Kolmogorov axioms-see Hájek (2002).
} 
true nor certainly false conditional on our evidence. This is part of what is involved in the claim that $G$ is an empirical bypothesis, or that $G$ is a hypothesis about how the world is constituted.

\section{2}

If that is right, then we can build inductive arguments pro or con the existence of God. Maybe we can find pieces of evidence that raise the probability of $G$; maybe we can find pieces of evidence that lower the probability of $G$; maybe we can find both types of evidence, and these different pieces of evidence will 'fight' for evidential support. But it may also be the case that there is no evidence available to us that has any bearing on the probability of $G$.

Theists-those who claim that God exists—purportedly have good undefeated evidence that gives overall support to $G$. For any proposition $\Phi$ and body of evidence $\Gamma$, let $r$ be the value such that, if $\operatorname{Pr}(\Phi \mid \Gamma) \geq r$, then a subject whose total evidence is $\Gamma$ is entitled to believe that $\Phi .{ }^{4}$ Theists would need to possess, then, some body of evidence $E$ such that $\operatorname{Pr}(G \mid E) \geq r$, and they would need to possess no further piece of evidence $E^{\prime}$ such that $\operatorname{Pr}(G \mid E$ $\left.{ }^{\wedge} E^{\prime}\right)<r$ (presumably, the evidence $E$ mentioned here is evidence that theists can share with their fellow human beings).

Atheists - those who claim that God does not exist-purportedly have good undefeated evidence that gives overall support to $\sim G$. They would need to possess, then, some body of evidence $F$ such that $\operatorname{Pr} \sim G \mid F) \geq r$, and they would need to possess no further piece of evidence $F$ such that $\operatorname{Pr}(\sim G \mid F$ ^

\footnotetext{
${ }^{4}$ In order for that consequent to hold, we should also assume that the subject is capable of forming a belief toward $\Phi$ on the basis of evidence $\Gamma$ (no one is entitled to believe something that one can only believe in a non-competent way). But this is not particularly important now.
} 
F) $<r$ (again, the evidence mentioned here is presumably evidence that atheists can share with their fellow human beings).

While there is just one way to go for the theist and one way to go for the atheist, the agnostic —or skeptic if you like—has more than one way to go. The agnostic refrains from claiming either that God exists or that God does not exist-he/she suspends judgment about $G$. In order for suspension of judgment to be the rational attitude for one to take toward a certain proposition, one's evidence need to be sufficiently neutral as to whether that proposition is true. There are two ways in which that might be the case.

First, one may be in a situation of evidential poverty - a situation, that is, in which one possesses no evidence pro or con the truth of a certain proposition. In the case at hand, agnostics may possess no body of evidence $D$ such that either $\operatorname{Pr}(G \mid D) \geq \operatorname{ror} \operatorname{Pr}(\sim G \mid D) \geq r$.

Second, one may be in a situation of evidential symmetry-a situation, that is, in which one possesses some evidence pro and some evidence con the truth of a certain proposition-but each counterbalances the other. Such a situation would be modeled as follows. Suppose a subject $S$ possesses some evidence $E$ such that $\operatorname{Pr}(G \mid E) \geq$ r. If S's total evidence were $E$, then $S$ would be epistemically entitled to believe that $G$. As it happens, though, $S$ has some further body of evidence $F$ such that $\operatorname{Pr}(\sim G \mid F) \geq r$, which is the same as to say that $\operatorname{Pr}(G \mid F) \leq 1-r$.

Now, notice that just as the threshold on $\operatorname{Pr}(\Phi \mid I)$ for epistemic entitlement to believe that $\Phi$ is $r$ (assuming that $\Gamma$ is the total evidence), so the threshold on $\operatorname{Pr}(\Phi \mid \Gamma)$ for epistemic entitlement to disbelieve that $\Phi$, or to believe that $\sim \Phi$, is $1-r$ (assuming again that $\Gamma$ is the total evidence), for any proposition $\Phi$ and body of evidence $\Gamma$. So for any value $s$ in the open interval $(1-r, r)$, if $\operatorname{Pr}(\Phi \mid \Gamma)=s$ and $\Gamma$ is $S$ 's total evidence, then $S$ is entitled to suspend judgment about $\Phi$. Just as there are thresholds on epistemic 
probabilities for epistemic entitlement to believe/disbelieve a proposition, so there are thresholds on epistemic probabilities for entitlement to doubt or to suspend judgment about a proposition.

Now apply that result to the scenario we have built above (evidential symmetry). We assumed that $S$ has some evidence $E$ in support of $G$ and also some evidence $F$ in support of $\sim G$. Assuming that $E$ and $F$ are all the relevant evidence that $S$ has concerning the truth of $G$, if $1-r<\operatorname{Pr}(G \mid E \wedge F)<r$, then $S$ is entitled to suspend judgment about the proposition that God exists.

So agnostics have two argumentative resources at their disposal: either we are in a situation of evidential poverty with respect to the hypothesis that God exists, or we are in a situation of evidential symmetry with respect to that hypothesis.

Some philosophers have explicitly offered probabilistic arguments pro the existence of God, using a bayesian framework. Most notably, Richard Swinburne (2004) makes use of traditional bayesian criteria for establishing the confirmation of hypotheses and the explanation of observable evidence, and argues that we have overall good evidence for believing that God exists. Among these criteria, two of them will be particularly relevant for the points I want to make.

First, how much support a certain body of evidence $E$ confers upon a certain hypothesis $H$ is dependent on the prior probability of $H$. This becomes clear as we look at Bayes' Theorem:

$$
\operatorname{Pr}(H \mid E)=\operatorname{Pr}(H) \times \operatorname{Pr}(E \mid H) \div \operatorname{Pr}(E) .
$$


As we increase the value $\operatorname{Pr}(H)$ and maintain the rest, so the value $\operatorname{Pr}(H \mid E)$ increases. As Swinburne himself points out (2004: 53), the prior probability of a hypothesis—or its probability before we have made some relevant observations $E$-is determined by its fit with our background knowledge $B$, its simplicity and its scope of application. The background knowledge $B$ is our general knowledge of how the world works, and it is supposed to figure as follows:

$$
\operatorname{Pr}(H \mid E B)=\operatorname{Pr}(H \mid B) \times \operatorname{Pr}\left(E \mid H^{\wedge} B\right) \div \operatorname{Pr}(E \mid B) .
$$

Now, a hypothesis $H$ is said to fit the background knowledge $B$ when it postulates similar types of entities, properties, relations and laws as the ones present in B. Similarly, the simplicity of $H$ is a matter of its not postulating more entities, types of entities, properties, relations and laws than the ones present in our background knowledge $B$. So $H$ is supposed to be as concise and economical as possible. Finally, the scope of a hypothesis is the range of objects about which it has implications. We will get back to these points in a moment.

Second, how much support a certain body of evidence $E$ confers upon a certain hypothesis $H$ is also determined by the explanatory power that $H$ has with respect to $E$. (This again becomes evident when we look at Baye's Theorem: as we increase the value $\operatorname{Pr}\left(E \mid H^{\wedge} B\right)$ and maintain the rest, so the value $\operatorname{Pr}\left(H \mid E^{\wedge} B\right)$ increases). Explanatory power is a matter of how likely the hypothesis makes the observable evidence. If $H$ entails $E$, for example, it cannot get better than that: the hypothesis makes sure that the evidence occurs.

So in the case at hand, where we want to determine the probability that God exists given our available evidence, we need to answer two crucial 


\section{Dossiê Naturalismo, Dissertatio - Volume Suplementar 02 | UFPel [2015]}

questions: (i) What is the prior probability of $G$ ? (ii) How much explanatory power $G$ has with respect to our shared observable evidence? When we address (i), we must check how well does $G$ fit with our common background knowledge, how simple $G$ is and what the scope of $G$ is. When we address (ii), we must check how likely is our shared observable evidence conditional on the existence of God. Let us turn to those questions now.

\section{4}

Let us consider, first, how well does $G$ fit with our background knowledge $B$. In order to do that, we must at least roughly establish what our background knowledge about the world is supposed to be. It will contain, among other things: causal information (e.g., normally fire causes smoke), ${ }^{5}$ temporal information (e.g., my parents were born before me), spatial information (e.g., the Earth and the Moon occupy and move through different regions of the solar system), statistical data (e.g., all observed ravens are black), psychological data (e.g., about how things feel and appear to us), conceptual relations (e.g., all humans are mortal), logical and mathematical principles (e.g., if $P$ and $P \rightarrow$ $Q$ then $Q$, if $x>y$ and $y>z$ then $x>z)$.

That much will suffice for our present purposes. ${ }^{6}$ The most important point is that $B$ is supposed to contain only knowledge that is maximally common between us. The more controversial a certain claim is, the more unqualified it is to be inserted in $B$.

\footnotetext{
${ }^{5}$ The inclusion of causal information in $B$ is independent of the fact that we may have a deflationary interpretation about causal claims (e.g., to the effect that purported causal relations are nothing more than associations or correlations between events/types of events). That observation generalizes to the other types of information that are included in $B$.

${ }^{6}$ This is what we call 'common background knowledge about the world'. Swinburne suggests that we start the probabilistic investigation about $G$ with a background knowledge devoid of any substantial content, with nothing but tautologies in it, and then start enriching it. But this has at most heuristic value for Swinburne's purposes, and at the end of the day it does not make a probabilistic difference if we start computing the 'pure' prior probability of $G$ and update it on substantial background knowledge or if we already start computing the prior probability of $G$ with that substantial information in $B$.
} 
Now, God is supposed to be an immaterial being, a conscious mind with no body or matter. God would have, for example, beliefs and intentions, as God is supposed to have knowledge of all knowable facts and also to be benevolent. But God would not need to have a nervous system, for example.

In our background knowledge, however, there is not a single example of a being with consciousness and intentionality but no such material structure. Statistically, every mind we purportedly know to exist has a physical medium (a medium by means of which that very mind manifests itself). ${ }^{7}$ No cognitive agent known to us lacks a brain. And no cognitive agent known to us lacks representations, or vehicles of information. How is God supposed to know things if God does not represent the world as being a certain way? And, if God does process information and handles representational items, how does he do that without a brain or something analogue to a brain?

On the face of that statistical data (all minds known to us have bodies and all of them process information), which is part of our background knowledge, it turns out that $\operatorname{Pr}(G \mid B)=p$ must be quite low. If we had started with a pure prior $\operatorname{Pr}(G)=0.5$, for example, we would not only have $\operatorname{Pr}(G \mid B)$ $<\operatorname{Pr}(G)$, but also quite a substantial difference $0.5-p$. Assuming again that $r$ is our upward threshold of evidential support that entitles one to believe a proposition, and that $1-r$ is our downward threshold of evidential support that entitles one to disbelieve a proposition, it could well be the case that $p \leq 1$ $-r$, in which case we would be entitled to disbelieve $G$. But since we are making pretty coarse grained estimations here, it could also be that $1-r<p<$ $r$, in which case we would be entitled to suspend judgment about $G$. Either way, we would not be entitled to believe that $G$ conditional on $B$. As far as $B$ goes, then, theism would not be the rational position.

${ }^{7}$ This is not to say that there is no immaterial substance. So far, we are just pointing out that there is no mind unaccompanied by a body in our background knowledge - and this is all that is needed for making our point here. 


\section{Dossiê Naturalismo, Dissertatio - Volume Suplementar 02 | UFPel [2015]}

That would not be the only information in $B$ that lowers the prior probability of $G$. The situation gets worse, at least if we assume that God is supposed to be the creator of the universe. Remember that the simplicity of $G$ is supposed to have a direct influence on the prior $\operatorname{Pr}(G \mid B)$, and that the simplicity of a hypothesis is a matter of its not postulating more entities, types of entities, properties, relations and laws than the ones present in B. But if God is supposed to be the creator of the universe, then he must have established some causal relation with the universe. But God is immaterial and the universe is material. So $G$ postulates a type of causal relation that differs from the one present in our causal claims in $B$.

Consider the causal facts that we ordinarily take ourselves to know. We purportedly know that my throwing the ball into the window may cause it to break, that the wind may lower the temperature of a certain place, that certain drugs may bring about health improvement/decay, etc. In these examples, what we have is physical causation: one physical event (or a whole set of physical events conjoined) causes a further physical event. In none of these cases we have a spiritual substance interacting causally with a material one.

You may think that mental causation fits the bill, though. You may think, that is, that our minds are immaterial substances that interact causally with our bodies, e.g. when desires purportedly cause bodily movements-in which case you are a substance dualist. That there is causation between a spiritual substance and a physical one in our cognition, however, is not itself part of our common knowledge (as substance dualism surely is not part of our common knowledge). For all we know, mental causation might be physical causation as well. It is not the case that everybody or almost everybody knows that spirits cause physical events— this is quite a controversial matter. 
So claims about immaterial substances maintaining causal relations with physical ones is not uncontroversial enough to be inserted in $B$. As long as $G$ postulates a new type of causal relation-an unknown type of relationthe prior $\operatorname{Pr}(G \mid B)$ will be even lower, for in that case $G$ does not fit $B$.

\section{5}

In the previous section we made the case that the prior probability of $G$ is quite low. In the present one, we will make the case that $G$ does not fare better when it comes to explanatory power. The problem concerning the explanatory power of theism is also related to problems with substance dualism.

The so-called mind-body problem was one the main reasons (maybe the main reason) for the demise of substance dualism throughout 20th century philosophy. What is the relationship between mind and body? If the mind is an immaterial substance and the body is a material one, how could they interact causally, if at all? Nowadays, we have versions of dualism (e.g. epiphenomenalism and parallelism) that try to avoid commitment to the idea that there is causal interaction between mind and body.

The thesis that God is the creator of the universe has ontological commitments in common with substance-dualism. Here we have the Goduniverse problem: what is the relationship between God and the universe? If God is immaterial and the universe is material, how could they interact causally, if at all? How could God produce movement and heat, for example? Maybe God could use a stick or some sort of dummy member as a tool. That way, we could have a bridge between God and the universe. But where did the stick/dummy member came from? And how could God interact with something even before that thing already exists? So it would seem that the probability that there is a material world conditional on the existence of God is 


\section{Dossiê Naturalismo, Dissertatio - Volume Suplementar 02 | UFPel [2015]}

very low indeed. Indeed, if it is impossible for the spiritual realm to interact causally with the physical realm, then that probability is 0 .

But if theism is supposed to have at least some explanatory power with respect to the observable evidence (the universe as we perceive it), then it must be because God created the universe as it is or, maybe, because God interacts with it, influencing the course of history. Could God indeed be the creator of the universe that is observable to us? Could God indeed interact causally with the universe?

Given again that we know of no causal relationship between spiritual and material substances, both things are unlikely conditional on $B$. Let $C$ be the proposition that God created the universe, or God interacts with the universe (it does not really make a difference for the present purposes which one you choose). Then, for reasons similar to the ones presented in the previous section, we would have a low $\operatorname{Pr}(C \mid B)=p$. Indeed, we only refrain from assigning $\operatorname{Pr}(C \mid B)=0$ because there is a bare possibility of causal interaction between spiritual and physical substances that is purportedly left open by $B$. Now, this is not the relevant result we want to draw per se-the issue here is the explanatory power of theism. The relevant conclusion to be drawn is the following. Let $E$ be a conjunction of evidential claims that can be summed up as The universe exists, and it appears to us to be a certain way $w$ (where $w$ describes the natural properties/relations we seem to observe in nature). Now, $E$ is actually entailed by $B$, so it would be fruitless to test the explanatory power of theism by computing the likelihood $\operatorname{Pr}\left(E \mid G^{\wedge} B\right)$. For here $B$ 'trumps' the relevance of $G$ to the truth of $E$.

The same applies of course to other hypotheses, e.g., cosmological theories. We have in our background knowledge propositions that entail that there is a universe, that the universe has such-and-such properties, etc. And what we expect from an empirical hypothesis is that is is able to explain the 
observable evidence. Since in the bayesian framework this is a matter of the likelihood of the hypothesis, $\operatorname{Pr}(E \mid H)$ or $\operatorname{Pr}(E \mid H \wedge B)$ depending on the case, we can test the explanatory power of an empirical hypothesis by striping out information from $B$ that entails $E$. In this way we can maintain a smaller set of propositions that are part of $B$ and generate a thinner, alternative background set $B^{-}$. Importantly, we can keep generalizations, conceptual relations and logical or mathematical claims in $B^{-}$. So, for example, the claim that All the causal relations that apparently manifested themselves so far are physical relations will be maintained, and so will $x$ is God if and only if $x$ is immaterial.

Given that much, if it is right to say that $\operatorname{Pr}(C \mid B)$ is low, then we can also conclude that $\operatorname{Pr}\left(E \mid G^{\wedge} B^{-}\right)$is low: if it is quite unlikely that God, which is an immaterial being, creates or interacts with the universe, then it is quite unlikely that there is a universe like the one we seem to observe conditional only on the existence of God and the information that 'survived' our selection to generate $B^{-}$(what we stripped out from $B$, remember, is solely a set of propositions that entail E). It would follow, then, that the hypothesis that God exists is not able to play any explanatory role with respect to $E$ for us.

\section{Conclusion}

So far, however, we can only conclude that $\operatorname{probably} \operatorname{Pr}(G \mid E \wedge B)<r$, and so that we are probably entitled to disbelieve $G$, that is, to believe that $\sim G .{ }^{8}$ But I want to be cautious and I do not want to prematurely jump to conclusions. This paper will have a sequence. Until then, I will follow the good old skeptical advice of suspending judgment on such complicated matters.

\section{REFERENCES}

${ }^{8}$ In this case, 'probably' means 'as far as I can see' or somesuch. 
HÁJEK, A. 'Interpretations of Probability', in Edward N. Zalta (ed.) The Stanford Encyclopedia of Philosophy (Winter 2012 Edition) 2002. Accessible through the URL:

<http://plato.stanford.edu/archives/win2012/entries/probability-interpret/> QUINE, W. V. O. 'Two Dogmas of Empiricism', The Philosophical Review 60, 1951, p 20-43.

SWINBURNE, R. The Existence of God. 2 ed. New York: Oxford University Press, 2004.

WILLIAMSON, T. The Philosophy of Philosopby (Blackwell/Brown Lectures in Philosophy). Malden MA: Blackwell Publishing, 2007. 